\title{
The truly random control as an extinction procedure*
}

\author{
JOHN J. B. AYRES and M. J. DeCOSTA
}

University of Massachusetts, Amherst, Mass. 01002

CS-alone trials or random presentations of CSs and USs were interpolated between Pavlovian defense conditioning and later measurement of the Pavlovian $\mathrm{CR}$ (conditioned suppression of barpressing). Although both procedures equally degraded the CS-US contingency, only the CS-alone procedure significantly weakened the previously established $C R$.

In Pavlovian forward conditioning, a US is more likely to occur if a CS has just occurred than if it hasn't. The CS is said to predict the US, and the US is said to be contingent on the CS (Rescorla, 1967). According to contingency theory, this contingency is responsible for conditioning, and eliminating the contingency is responsible for extinction (Rescorla, 1967).

Ayres \& Benedict (1970) subjected several groups of rats to a conditioning procedure in which the US was perfectly contingent on the $\mathrm{CS}$; then they attempted to degrade the contingency by (1) presenting CSs alone (CSa procedure), (2) presenting CSs and USs in a "truly random" fashion (TR procedure), or (3) presenting USs alone. Then, using as an index of conditioning the extent to which the CS suppressed a dipper licking response, they measured the amount of residual conditioning in the various groups. They found that only the CSa procedure had weakened the previously established CR.

Unfortunately, in the comparison of the CSa and TR procedures, the contingency (by chance) was not degraded as much by the TR as by the CSa trials.

The purpose of the present study was to compare again the efficacy of the CSa and TR extinction procedures. Care was taken to ensure that the contingency was degraded equally by both procedures.

\section{SUBJECTS}

The Ss were 36 male albino rats 90 days old on arrival from Gofmoor Farms, Westboro, Massachusetts. They were housed individually and fed freely for 7 days. Then over a 5-day period they were fed $3-5 \mathrm{~g}$ daily, reducing them to $80 \%$ of their free-feeding weights, at which they

* Supported by a grant to John J. B. Ayres from the Faculty Research Council of the University of Massachusetts and by Grant MH-18661-01 from the National Institute of Mental Health. We wish to thank Dr. Gus Lumia for his comments on the manuscript. were maintained throughout the study. Water was always available in their home cages.

\section{APPARATUS}

Six Gerbrands operant conditioning chambers with left-side dipper feeders were housed in ventilated $2-\mathrm{ft}$ cubes of .5-in. plywood lined with acoustical tile. A 2-ft sheet of Masonite covered the floor of each cube. Each barpress was reinforced throughout the study with a 4-sec presentation of $8 \%$ sucrose in a .I-cc dipper cup. The CS was the onset of a $1,000 \cdot \mathrm{Hz} \quad 84 \cdot \mathrm{dB}$ tone and the simultaneous of fset of an 87-dB white noise normally on for background masking. Scrambled grid shocks of $1.6-\mathrm{mA}$ intensity from six Grason-Stadler E1064 shock sources served as USs. The chambers were illuminated by a $28 \cdot \mathrm{V}$ cue lamp centered over the dipper hole and mounted $95 \mathrm{~mm}$ above the floor.

\section{PROCEDURE}

Preliminary training consisted of the following: Ss were first trained to lick $8 \%$ sucrose from the dippers and then were given $15 \mathrm{~min}$ of magazine training in which the frequency of free 4-sec dipper presentations gradually declined. During this session, the dipper was also raised for $4 \mathrm{sec}$ each time $S$ barpressed. Over the next 3 days, barpressing was shaped if necessary. Each $S$ was required to make a total of 180 responses in the course of the 3 days, including 90 on the last day of shaping. Each response was reinforced during these sessions and during all of the following sessions in which barpressing was permitted.

Starting on the day after the last shaping session, each $\mathbf{S}$ was exposed to 15 consecutive sessions given at about the same time daily. Unless otherwise noted, all sessions were $15 \mathrm{~min}$ long. The first 3 were pretest sessions designed to measure the unconditioned effects of the CS on barpressing. CSs were presented for $1 \mathrm{~min}$ in Minute 6 and Minute 10 , while Ss barpressed for sucrose.

The next two sessions were Pavlovian conditioning sessions; in each session all Ss got 1020 -sec CSs, paired with 10 2-sec shock USs of 1.6-mA intensity. US onset followed CS offset by $45 \mathrm{msec}$. Inter-CS intervals were identical for all $\mathrm{Ss}$ and ranged from 19 to 208 sec on the first conditioning day and from 24 to $242 \mathrm{sec}$ on the second. Pairings were given "off the baseline," that is, Ss were blocked from the bar by a four-walled insert so that the baseline response (barpressing) was not permitted.

The next two sessions were Pavlovian extinction sessions, each $20 \mathrm{~min}$ long. These were the only sessions in which treatments differed between groups. The purpose of these extinction sessions was to reduce the CS-US contingency to the same extent for both the CSa and TR groups, while leaving it unchanged for a control group. In each session, $S s$ in Group CSa got 15 presentations of the $20-\mathrm{sec}$ CS without shocks; $S$ in Group TR got $15 \quad 20-\mathrm{sec}$ CSs and 15 2 -sec shock USs distributed randomly and independently throughout the session. CSs and USs overlapped seven times by chance over the course of the two extinction sessions. Finally, a control group (Group No-ext.) received neither CSs nor USs, but did get the same handling and exposure to the apparatus that $S s$ in the other groups got. Like the conditioning trials, Pavlovian extinction trials were also conducted off the baseline. That the CS-US contingency was actually reduced equally for the CSa and TR groups can be shown as follows: Over the combined conditioning and extinction sessions, Group CSa got 50 CSs, of which 20 were paired with USs. Therefore, at the end of extinction, the P(US |CS) for this group was .40 . No USs ever appeared alone; therefore, $P(U S \mid \overline{\mathrm{CS}})$ was 0 . The degree of CS-US contingency was $\mathrm{P}(\mathrm{US} \mid \mathrm{CS})-\mathrm{P}(\mathrm{US} \mid \overline{\mathrm{CS}})$ or .40 . Over the combined conditioning and extinction sessions, Group TR got 50 CSs, of which 27 were paired with USs so that P(US । CS) was .54. In addition, 23 of the 160 non-CS intervals ${ }^{1}$ contained USs so that the $\mathrm{P}(\mathrm{US} \mid \overline{\mathrm{CS}})$ was .14. The degree of contingency for the TR group was, therefore, .54-.14, or .40 , at the end of extinction. Thus, the degree of contingency was reduced equally for both groups.

In the next two sessions, Ss were allowed to recover their baseline barpress rates so that meaningful suppression measures could be obtained in later sessions. Each S was allowed 100 reinforced responses in each session, then was removed from the box.

The final six sessions were test sessions designed to measure the efficacy of the Pavlovian extinction 


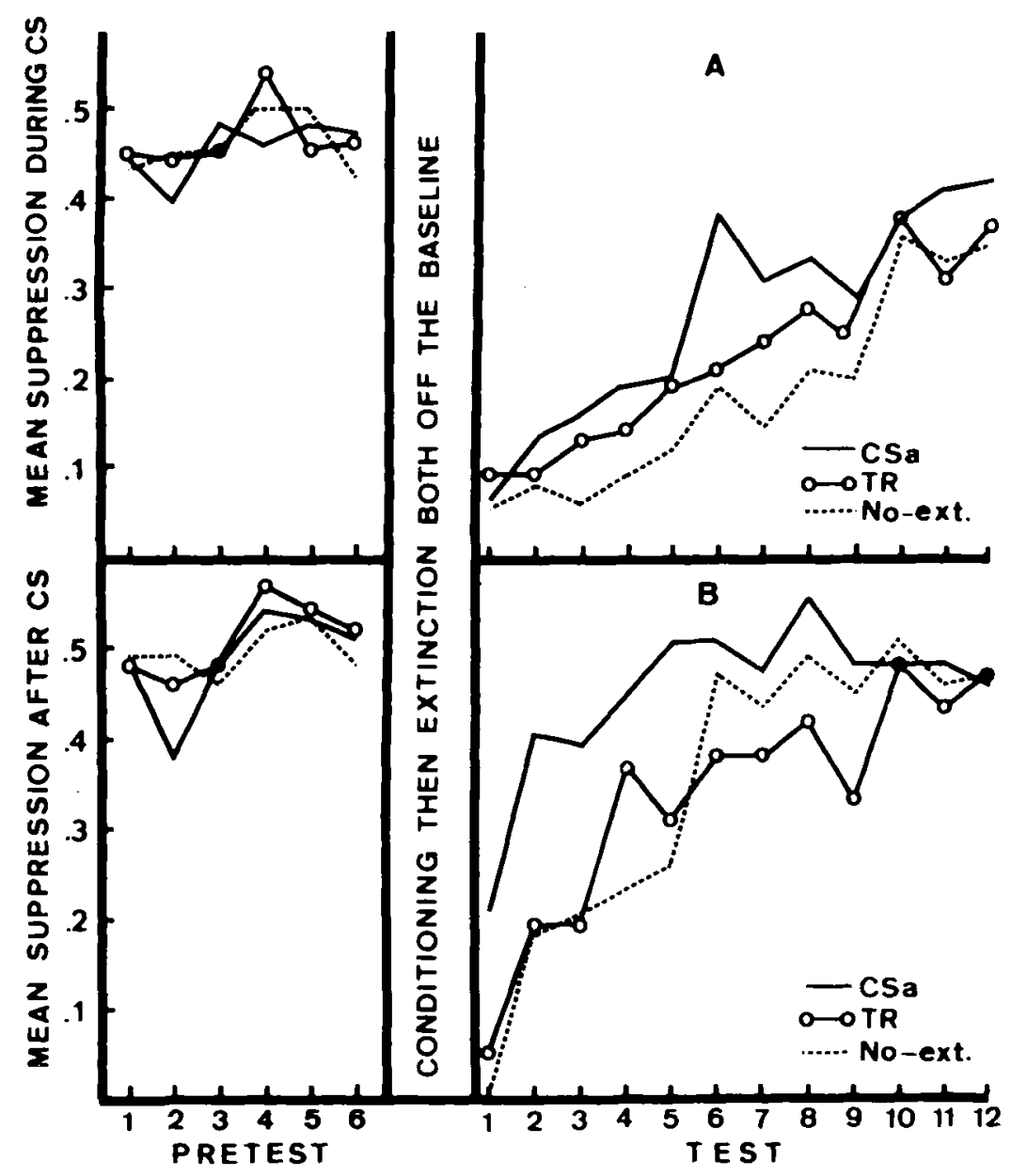

TRIALS

Fig. 1. Conditioned suppression during the CS (Panel A) and 1 min after the CS (Panel B) for groups receiving either a CS-alone procedure, a truly random procedure, or no extinction interpolated between conditioning and testing. In plotting data points, a "scoreless" trial was handled as follows: if $S$ failed to respond before and during (or after) a CS, he received on that trial the mean score from his two nearest trials. Statistically, this procedure supported the same conclusions as analyses which simply ignored these trials.

trials. They were identical to the pretest sessions.

As in previous work, the apparatus cues in the Pavlovian conditioning and extinction sessions (shock days) differed from those in all other sessions. On shock days a four-walled Masonite insert with .75 -in. vertical black and white stripes was placed inside the conditioning chamber, blocking Ss from the bar. The voltage across the cue lamp, which provided the only illumination in the chamber, was increased from the normal 6 to $26 \mathrm{~V}$; white paper was placed in the bottom of the litter tray to increase reflectance onto the striped inserts. On nonshock days the Masonite insert was removed and the grid floor covered with an aluminum sheet held down with spring clips.

\section{TREATMENT OF DATA}

Two indices of suppression were used. One assessed the extent of suppression during the CS. It was defined as $D /(B+D)$, where $D$ represents the number of responses occurring during the $\mathrm{CS}$ and $\mathrm{B}$ the number in the $1 \mathrm{~min}$ before the CS. The second assessed the extent of suppression in the $1 \mathrm{~min}$ after the CS. It was defined as $A /(B+A)$, where $A$ denotes the number of responses after the $C S$ and $B$ the number in the $1 \mathrm{~min}$ before. Both measures vary from 0 (maximum suppression) through .5 (no effect) to 1.0 (facilitation).

$$
\text { RESULTS }
$$

Figure 1A shows the suppression that occurred during the $\mathrm{CS}$ and Fig. 1B, the suppression in the $1 \mathrm{~min}$ after the CS. The left part of each figure shows the suppression to the CS during the pretest trials. On these trials, the groups did not differ either in terms of their suppression ratios or their pre-CS rates (not shown).

of more interest than the pretest data are the results shown at the right of each figure. Here, suppression following of $f$-the-baseline conditioning and extinction is shown. Both Panels $A$ and $B$ show that CSa trials given off the baseline produced a transfer of extinction relative to the no-extinction control procedure. Both suggest that TR trials given off the baseline produced less transfer of extinction than did CSa trials. In contrast to the earlier finding of Ayres and Benedict, however, there was a nonsignificant tendency for the TR procedure to produce some transfer (at least according to the during measure).

Since the direction of the differences between groups was clearly predicted on the basis of previous data and theoretical expectations, the reliability of the results was assessed using one-tailed Wilcoxon rank sum tests. These showed that Group CSa suppressed less than Group No-ext., both during and after the CS (ps $<.05$ and .005 , respectively). They also showed that Group CSa suppressed less than Group TR after the CS $(p<.01)$, and they failed to show any difference between Groups TR and No-ext. either during or after the CS. After completion of this study, 12 additional animals were run under the No-ext. procedure in connection with another experiment. Inclusion of their data in the statistical analysis increased the reliability of the difference between Groups CSa and No-ext. on the during measure (new $\mathrm{p}<.01$ ). However, the difference between groups TR and No-ext. remained unreliable.

One-tailed Wilcoxon tests also failed to reveal any differences in the groups' pre-CS response rates during testing. Thus, interpretation of the suppression data is uncomplicated by between-group differences in baseline rates.

\section{DISCUSSION}

In agreement with previous work (Ayres \& Benedict, 1970), CSa trials, but not TR trials, produced reliable transfer of extinction when given between conditioning and later measurement of the Pavlovian CR. Apparently, even though the CS-US contingency was degraded by the TR procedure, the expected weakening of the CR did not occur. Perhaps the shocks that the TR Ss received $72 \mathrm{~h}$ before testing made them more fearful during the critical tests than the other groups were. Perhaps their greater general level of fear amplified their suppression to the CS. However, if 
they were more fearful, then they should have had lower pre-CS response rates; but, the pre-CS rates did not differ reliably among groups.

An alternative hypothesis is that the important variable in the extinction of a fear CR is not the extent to which a CS-US contingency is degraded, but rather the extent to which the $C R$ is elicited in the absence of contiguous reinforcement. According to this view, the ability of the TR procedure to weaken a $C R$ should vary inversely with the CS-US density or contiguity during the TR procedure. Although the CS-US contiguity was much less in the present TR procedure than in earlier work, seven chance pairings still occurred. The present data are consistent with the view that these chance pairings were sufficient to retard extinction or to "reinstate" (Campbell \& Jaynes, 1966) the previously established CR.

The present findings are also consistent with a partial reinforcement interpretation. Relative to the CSa group, the TR group received a partial reinforcement procedure in that some of its pairings were interspersed among nonpairings. Hence, its rate of extinction in the critical test might be expected to be relatively slow. Recent results (Benedict, 1971) argue against this interpretation. Benedict subjected groups of rats to different truly random control procedures. The groups received the same number of pairings and nonpairings but differed as to the location of these events. One group experienced some of its accidental pairings before it experienced nonpairings. The second group did not. The first group showed strong evidence of conditioning in a later test; the second did not. Since the groups received the same percentage of reinforced trials, their behavioral differences cannot be explained in terms of partial reinforcement perse. However, the data are consistent with the reinstatement account of the present findings. According to this account, conditioning occurred in Benedict's first group because of the first few chance pairings. Later chance pairings reinstated the conditioning and prevented its extinction. Even though the second group received the same percentage of reinforced trials, conditioning did not occur on the basis of those trials because of the negative transfer (e.g., latent inhibition or conditioned inhibition) from the nonpairings that occurred first (Lubow \& Moore, 1959; Rescorla, 1969).

\section{REFERENCES}

AYRES, J. J. B., \& BENEDICT, J. O. Stimulus contingencies in the extinction of fear. Paper presented at the meeting of the Psychonomic Society, San Antonio, Texas 1970 .

BENEDICT, J. O. Factors affecting conditioned suppression in the absence of a CS-US contingency. Unpublished Master's thesis, University of Massachusetts, 1971.

CAMPBELL, B. A., \& JAYNES, J. Reinstatement. Psychological Review, 1966, 73, 478-480.

LUBOW, R. E. \& MOORE, A. V. Latent inhibition. The effect of frequency. Journal of Comparative \& Physiological Psychology, 1959.52, 415-419.

RESCORLA, R. A. Pavlovian conditioning and its proper control procedures. Psychological Review, 1967, 74, 71-80. RESCORLA, R. A. Conditioned inhibition of fear resulting from negative CS-US contingencies. Journal of Comparative \& Physiological Psychology, 1969. 67. 504-509.

\section{NOTE}

1. An "interval" is a time period equal to the CS duration. In the combined acquisition and extinction session there were 210 such intervals: 50 were CS intervals and 160 were non-CS intervals. 